\title{
Sosa on Knowledge, Assertion and Value
}

\author{
Christoph Kelp
}

Received: 13 September 2013/ Accepted: 26 March 2014/Published online: 18 April 2014

(C) Springer Science+Business Media Dordrecht 2014

\begin{abstract}
This paper takes issues with a couple of recent arguments due to Ernest Sosa according to which (i) knowledge is the norm of assertion and (ii) the thesis that knowledge is specially valuable is equivalent to the thesis that knowledge is the norm of assertion. It is argued that while both of these arguments fail, an argument that knowledge is the norm of belief and that the thesis that knowledge is specially valuable is equivalent to the thesis that knowledge is the norm of belief may yet be defensible.
\end{abstract}

Keywords Epistemology $\cdot$ Value of knowledge $\cdot$ Norms of assertion · Ernest Sosa

\section{Introduction}

To explain why knowledge is of special value is to solve the value problem in epistemology, that is, the problem of explaining why knowledge is more valuable than epistemic standings falling short of knowledge such as true or justified belief. One promising strategy to tackle the value problem is by arguing that knowledge has normative properties that epistemic standings short of knowledge do not have. For instance, if it can be shown that knowledge (but not true or justified belief, etc.) is the norm of assertion, one will also have explained the special value of knowledge. After all, only knowledge will entitle one to assert and so it is better to know than to have beliefs falling short of knowledge.

In a couple of recent pieces Sosa $(2010 b, 2011)$ has pursued just such a line. There he aims to show that knowledge is the norm of assertion and to argue from the

C. Kelp $(\bowtie)$

Centre for Logic and Analytic Philosophy, KU Leuven, Kardinaal Mercierplein 2,

3000 Louvain, Belgium

e-mail: christoph.kelp@hiw.kuleuven.be 
knowledge norm of assertion to the special value of knowledge. In fact, Sosa thinks the latter argument can be strengthened as its converse (if knowledge is of special value, then knowledge is the norm of assertion) is defensible also. According to Sosa, then, (i) knowledge is the norm of assertion and (ii) the thesis that knowledge is of special value is equivalent to the thesis that knowledge is the norm of assertion.

This paper argues that while Sosa's arguments for both (i) and (ii) fail, an argument that knowledge is the norm of belief and that the thesis that knowledge is specially valuable is equivalent to the thesis that knowledge is the norm of belief may be defensible. More specifically, in what follows I will first outline Sosa's relevant arguments (Sect. 2) and then argue in some detail that they both fail (Sect. 3). Finally, in Sect. 4, I will venture on a rescue mission on behalf of Sosa.

\section{Sosa's Arguments}

\subsection{The Knowledge Norm of Assertion}

Before moving on to Sosa's actual argument for the knowledge norm of assertion, it will be necessary to first take a brief look at Sosa's accounts of performance, belief and means-ends action, which the argument presupposes. Let's begin with performances.

According to Sosa, performances with an aim fall under 'AAA structure'. This means they can be evaluated in terms of whether they attain the aim (i.e. whether they are successful), whether they are adroit (i.e. competent) and whether they are apt (i.e. the performance's success manifests its competence) (Sosa 2010b: 173). Aptness also constitutes the minimum standard for performances with an aim: any inapt performance is thereby defective. Otherwise put, performances with an aim are proper, i.e. non-defective, only if they are apt (henceforth I will also refer to this thesis as 'Aptness standard of performances') (Sosa 2010b: 175).

Sosa takes beliefs to constitute a special case of performances. More specifically, beliefs are performances that aim at truth (henceforth also 'Truth aim of belief') and thus fall under AAA structure. One of Sosa's core epistemological thesis is that knowledge is apt belief ('Aptness account of knowledge'). ${ }^{1}$

Moving on to means-end actions, they also constitute a kind of performance with an aim and admit of AAA evaluation. Moreover, means-end actions are partly constituted by a means-end belief ('Means-end constitution thesis'). Crucially, a means-end action is apt only if the corresponding means-end belief is also apt ('Means-end aptness thesis') (Sosa 2010b, 174).

With these points in play, here is my explication of Sosa's (2010b: 175-176) argument for the knowledge norm of assertion:

A1 One's assertion that $p$ is sincere only if it is made "in the endeavour to thereby assert with truth" - in other words, only if one asserts that $p$ as a means to thereby assert $p$ with truth.

\footnotetext{
${ }^{1}$ Sosa (2010b: 173). For more on Sosa's account of performances, belief and knowledge see e.g. Sosa (2007, 2010a, 2011).
} 
A2 One's sincere assertion that $p$ is a means-end action. [A1]

A3 One's sincere assertion that $p$ essentially involves the belief that asserting that $p$ is a means to thereby assert that $p$ with truth.

A4 One's sincere assertion that $p$ is apt only if one's belief that asserting that $p$ is a means to thereby assert that $p$ with truth is apt also. [A3, Means-end aptness thesis]

A5 The belief that asserting that $p$ is a means to thereby assert that $p$ with truth is equivalent to the belief that $p$.

A6 One's sincere assertion that $p$ is apt only if one aptly believes that $p$. [A4, A5]

A7 One's sincere assertion that $p$ is apt only if one knows that $p$. [A6, Aptness account of knowledge]

A8 Sincerity is an epistemic norm of assertion: One's assertion that $p$ is epistemically non-defective only if it is sincere.

A9 One's assertion that $p$ is epistemically non-defective only if one knows that $p$. [A7, A8]

A9 is tantamount to the thesis that knowledge is an epistemic norm of assertion.

\subsection{The Equivalence Argument}

Let's move right on to Sosa's argument that the knowledge norm of assertion is equivalent to the thesis that knowledge is of special value. Again, in order to understand Sosa's argument it will be necessary to first look at some relevant background theory. Most important here is Sosa's conception of belief. Sosa devotes a significant part of his paper to develop his preferred affirmative conception of belief (henceforth also 'ACB' for short) according to which one believes that $p$ if and only if one is disposed to affirm that $p$ (Sosa 2010b: 172). The notion of affirmation is defined as either asserting publicly or assenting privately (Sosa 2010b: 172). ACB is motivated by the improvements it makes on what Sosa presumably considers as its strongest rival, a threshold conception of belief according to which one believes that $p$ if and only if one's confidence that $p$ surpasses a certain threshold (Sosa 2010b: §I).

Sosa adopts two further theses that are of relevance to his argument: According to the first, if assertion is governed by a knowledge norm, then affirmation is governed by a knowledge norm also ('Assertion/affirmation parallel') (Sosa 2010b: 177). While Sosa does not offer explicit support for this thesis, one might think that it is plausible enough given his definition of affirmation. ${ }^{2}$ The second states that affirmation that $p$ is non-defective if and only if the disposition to affirm that $p$ is ('Affirmation/disposition to affirm parallel') (Sosa 2010b: 177).

Here is how Sosa states the first half of the argument:

(ix) Knowledge is the epistemic norm of affirmation: that is, to affirm that $p$ without epistemic defect requires knowing that $p$. [A9, Assertion/affirmation parallel]

\footnotetext{
${ }^{2}$ In fact, Sosa also needs the converse of Assertion/affirmation parallel. However, given the definition of affirmation the converse seems no less plausible than Assertion/affirmation parallel itself.
} 
(x) Knowledge is the norm of belief: that is, to believe that $p$ - to be disposed to affirm that $p$-without epistemic flaw requires knowing that $p$. [(ix), ACB, Affirmation/disposition to affirm parallel]

(xi) Merely true belief is defective by comparison with the corresponding knowledge. [(x)]

(Sosa 2010b: 179)

And here comes the second half:

(xii) Merely true belief is defective by comparison with the corresponding knowledge.

(xiii) To believe that $p$-to be disposed to affirm that $p$-without epistemic defect requires knowing that $p$. [(xii), ACB, Truth aim, Aptness conception of knowledge, Aptness standard]

(xiv) Knowledge is the epistemic norm of affirmation: to affirm that $p$ without epistemic defect requires knowing that $p$. [(xiii), Affirmation/disposition to affirm parallel ${ }^{3}$ ]

(Sosa 2010b: 179)

\section{Problems with Sosa's Arguments}

In this section, I will give voice to some worries I have about Sosa's arguments. I will begin with the equivalence argument and, more specifically, with the assumptions underlying the argument.

\subsection{Sosa's Equivalence Argument in Trouble}

Let's focus on ACB, the affirmative conception of belief. Recall that Sosa motivates ACB by comparison with a threshold conception of belief, according to which one believes that $p$ if and only if one's confidence that $p$ surpasses a certain threshold. While improving on the threshold conception is certainly a merit of $\mathrm{ACB}$, in and of itself this fact does little to make plausible the thesis that ACB is correct. In fact, a closer look reveals that there are significant problems on the horizon.

Suppose $S_{1}$ is a notorious liar on the question whether $p$. He is disposed to assert that $p$ even though he himself does not believe that $p$. According to ACB, this is impossible. Given that $S_{1}$ is disposed to assert that $p$, he is disposed to either assert that $p$ in public or assent to $p$ in private. By Sosa's definition of affirmation, $S_{1}$ is disposed to affirm that $p$ and, by ACB, he believes that $p$. Given, furthermore, that $S_{1}$ is disposed to assent to not- $p$ in private, by Sosa's definition, $S_{1}$ is also disposed to affirm that not- $p$ and, by ACB, also believes that not- $p$. However, this seems to be the wrong verdict about this case. Cases like $S_{1}$ 's are not cases in which an agent has

\footnotetext{
${ }^{3}$ Notice that Sosa's argument falls just short of establishing the entailment of the knowledge norm of assertion by the special value of knowledge. The converse of Assertion/affirmation parallel in conjunction with (xiv) will fill the gap.
} 
contradictory beliefs. They are cases in which the agent believes one thing but is disposed to assert something else.

The obvious way of trying to remedy this defect is by holding that it is the disposition to assent in private that really matters for belief. This will get the case of $S_{1}$ right. However, problems still remain. $S_{2}$ may be disposed to be insincere towards herself when she asks herself (i.e. in private) the question whether $p$ : she may be disposed to assent to $p$ in private even though she does not believe that $p$. If so, by the modified version of ACB, she will count as believing that $p$. The same problem arises again.

A more promising modification of ACB places an additional sincerity condition on affirmation. According to the resulting view (call it ' $\mathrm{ACB}^{\star}{ }^{\star}$ '), one believes that $p$ if and only if $p$ is what one is disposed to affirm if one affirms sincerely. One obvious problem with this view is that, according to a standard account, sincerity of affirmation is understood in terms of belief: one's affirmation that $p$ is sincere only if one believes that $p$. The standard account is obviously not available to champions of $\mathrm{ACB}^{\star}$ as it renders the view blatantly circular.

That said, Sosa offers a slightly different account of sincerity according to which an assertion is sincere only if it is made in the endeavour to thereby assert with truth. And presumably what goes for assertion also holds, mutatis mutandis, for affirmation. But now recall that, in order to get his argument for the knowledge norm of assertion off the ground, Sosa construed assertion in the endeavour to assert with truth as a means-end action that essentially involves the belief that asserting that $p$ is a means to thereby assert that $p$ with truth. Given that this is so and given that what goes for assertion also holds, mutatis mutandis, for affirmation, we get the result that sincere affirmation essentially involves the belief that affirming that $p$ is a means to thereby affirm that $p$ with truth. Now, by $\mathrm{ACB}^{\star}$, the belief at issue here turns out to be a disposition to affirm if one affirms sincerely. However, sincerity here essentially involves a means-end belief, which is understood in terms of a disposition to affirm if one affirms sincerely, which in turn, involves a means-end belief... $\mathrm{ACB}^{\star}$ in conjunction with Sosa's account of sincerity thus leads to a vicious regress.

Now, Sosa might venture to avoid the regress by claiming that, unlike assertion, sincere affirmation does not essentially involve the means-end belief. The question remains, however, how sincerity of affirmation is then to be understood. More importantly, however, given the importance of the parallel claim about assertion in Sosa's argument for the knowledge norm of assertion, if he were to maintain that affirmation is unlike assertion in this respect, he would jeopardise the motivation for Assertion/affirmation parallel, the claim that if knowledge is the norm for assertion, then it is also the norm of affirmation. His equivalence argument would face a different problem at another end.

A further problem for both $\mathrm{ACB}$ and $\mathrm{ACB}^{\star}$ stems from (certain varieties of) unconscious beliefs. $S_{3}$ 's belief that he was abused as a child by a family member is repressed. Much of his conscious life is spent on avoiding this question altogether. When asked he acts evasively, seems not to understand. One could imagine an extreme version of the case in which confrontation with the question causes him so 
much stress that he simply blacks out, not remembering the episode at all. Yet, $S_{3}$ may have the belief. It is manifested in various actions including the lengths he goes to in order to avoid certain parts of the family, his extreme reaction (in the black out case) when confronted with the issue, etc. Beliefs like this pose a problem for both $\mathrm{ACB}$ and $\mathrm{ACB}^{\star}$ since here belief seems to be present even though there is no disposition to affirm either way (nor a disposition to suspend judgement).

Couldn't Sosa respond that he is interested only in conscious belief? Not plausibly. After all, even repressed beliefs are performances in Sosa's sense and assessable in terms of success, competence and aptness. $S_{3}$ 's repressed belief that he was abused may well have been aptly acquired and sustained. That's how it differs from $S_{4}$ 's repressed belief that white people cannot attain an IQ higher than 65. $S_{3}$ 's but not $S_{4}$ 's repressed belief is apt. $S_{3}$ has repressed knowledge, while $S_{4}$ 's is a repressed false belief.

There is thus reason to believe that $\mathrm{ACB}$ and $\mathrm{ACB}^{\star}$ are both false. If so, there remains a gap in Sosa's equivalence argument. And it may be worth noting that it is not clear that a different, more adequate conception of belief will fill it. The reason for this has already briefly surfaced. Sosa's argument also relies on Assertion/ affirmation parallel (and its converse). While this thesis is rather plausible (as is its converse), especially given that affirmation is understood along the lines of Sosa's definition, once the link between belief and affirmation is severed, it will no longer do the work Sosa needs it to do. What's more, it is far from clear that the corresponding principles will be equally plausible given a more adequate account of belief-that is, one that also countenances $S_{3}$ and $S_{4}$ 's repressed states as beliefs. In other words, while it is plausible that if knowledge governs assertion, then it will also govern affirmation (and conversely), where affirmation is construed as either public assertion or private assent, it is far from clear that it should be equally plausible that if knowledge governs assertion, then it will also govern belief (or conversely), where belief is understood in such a way as to include states that have little or no connection with either affirmation or assertion. The falsity of ACB and $\mathrm{ACB}^{\star}$ leaves a gap in Sosa's argument that isn't easily filled.

\subsection{Sosa's Argument for the Knowledge Norm in Trouble}

What about Sosa's argument that knowledge is the norm of assertion? Sosa claims that sincerity is an epistemic norm of assertion. How plausible is this?

Let's start with a proposed counterexample to the knowledge norm due to Jennifer Lackey $(2007,2008)$ in which the speaker makes a 'selfless' assertion, i.e. she asserts something she does not herself believe: $S_{5}$ is a teacher at the local high school and a devout creationist. However, she recognises that all the evidence speaks in favour of evolutionary theory and since she thinks she ought to teach the theory that is best supported by the evidence, she asserts various truths of evolutionary theory in the classroom. The thought now is that the teacher's assertions are non-defective. At the same time, since $S_{5}$ is a creationist, she does not herself believe what she asserts and hence does not know the relevant truths of evolutionary theory. 
Sosa responds to this case by drawing a distinction between asserting in one's own person and asserting as occupier of a role and claims that the sincerity norm, from which he ventures to derive the knowledge norm, applies only to assertions in one's own person. The fact remains, or at any rate remains unchallenged by Sosa, however, that the assertions in these cases can be non-defective. If that is right, isn't the right conclusion to draw that assertion is not after all governed by a sincerity norm, rather than that there exists a subclass of assertions that is governed by such a norm? Let's shelve this question for a moment. Notice that, in any case, selfless assertions can be divided into defective and non-defective and even into epistemically defective and non-defective assertions. $S_{5}$ 's selfless assertions of truths of evolutionary theory are epistemically non-defective, while $S_{6}$ 's selfless assertions of Lamarckianism aren't. This suggests that there is an epistemic norm governing assertion besides the sincerity norm.

How plausible is it that sincerity is an epistemic norm of assertion anyway? Consider the case of the consistent liar, also due to Lackey $(2006,2008)$, in which the effects of a patterned insincerity in assertion is cancelled out by a patterned unreliability in belief: Whenever $S_{7}$ asserts that she is seeing a horse, she believes that she is seeing a deer, whenever she asserts that she is seeing an elephant she believes that she is seeing a zebra, etc. At the same time, whenever she sees a horse, she will come to believe that she is seeing a deer, whenever she is seeing an elephant, she will be led to believe that she is seeing a zebra, etc.

Consider $S_{7}$ 's assertion that a deer is present. Her assertion is insincere: $S_{7}$ does not believe that a deer is present and also does not assert in the endeavour to assert with truth. Is her assertion epistemically defective? There is reason to think that it isn't. As Lackey rightly points out, $S_{7}$ 's audience can acquire testimonial knowledge from $S_{7}$ 's assertions. In other words, $S_{7}$ 's assertion can be a source of knowledge for other agents. It is hard to see how this could be if her assertion were epistemically defective. After all, epistemically defective sources, such as malfunctioning instruments and perceptual systems, generally are not sources of knowledge. More robustly, being a source of knowledge is plausibly a way of being an epistemically non-defective source. ${ }^{4}$ The case of $S_{7}$ thus suggests that an assertion can be insincere, whilst being epistemically non-defective. As a result, there is reason to think that sincerity is not an epistemic norm of assertion.

\footnotetext{
${ }^{4}$ One might think that there are problems with this claim. Suppose I know that my watch is running $10 \mathrm{~min}$ late. I look at it and see that it reads 5:00. Since I know that my watch is running 10 min late, I infer that it is 5:10. Intuitively, I come to know that it is 5:10. Hence, my watch is a source of knowledge for me. At the same time, it evidently isn't a source of knowledge for many other people. Now, what does that mean concerning the epistemic non-defectiveness of my watch? This kind of difficulty can be avoided by further restricting the notion of source of knowledge at issue here. One (perhaps not the only) way of achieving this is by requiring the source to be a source of non-inferential knowledge in the sense that competent users of the source can acquire non-inferential knowledge from this source. What we get, then, is that being a source of non-inferential knowledge is a way of being an epistemically non-defective source. It is easy to see that this avoids the problem of the watch case. At the same time, it still serves to generate the problem for the sincerity norm. After all, the testimonial knowledge $S_{7}$ 's audience acquires from $S_{7}$ 's assertion is non-inferential. Hence, $S_{7}$ 's assertion is a source of non-inferential knowledge and so, by the revised version of the above claim, epistemically non-defective.
} 
It thus becomes clear (i) that we need an epistemic norm of assertion besides the sincerity (and hence the knowledge) norm and (ii) that sincerity is not plausibly an epistemic norm of assertion. With these results in play, let return to the question previously shelved: How plausible is Sosa's suggestion that sincerity is an epistemic norm of assertion, but it is restricted to assertions in one's own person vis-à-vis the alternative suggestion that the non-defectiveness of selfless assertions shows that sincerity is not a norm (epistemic or otherwise) governing assertion in the first place? My verdict is that it isn't very plausible at all. We don't need sincerity to understand how assertion can be governed by a norm, epistemic or otherwise. That is to say, there is no reason to think that we will suffer any losses from taking cases of selfless assertion at face value as counterexamples not only to a knowledge norm but also to a sincerity norm of assertion. That said, for present purposes, we don't need so strong a claim. After all, Sosa's crucial premise we are targeting is that sincerity is a specifically epistemic norm of assertion. For that reason, we can rest content with the weaker claim that sincerity is not an epistemic norm of assertion, at least for the purposes of this paper. Again, the weaker claim derives support from the fact that we don't need sincerity to understand how assertion can be governed by an epistemic norm and so must not be expected to suffer any losses from taking cases of selfless assertion at face value as counterexamples to Sosa's crucial premise. Given that this is so, Sosa's proposed restriction of the sincerity norm retains little motivation. His argument for the knowledge norm fails on the grounds that sincerity is not an epistemic norm of assertion.

\section{Rescue Mission}

Sosa set out to argue that knowledge is the norm of assertion and that the knowledge norm of assertion is equivalent to the special value of knowledge. I have argued that there are problems with both of Sosa's arguments. So, let's ask what, if anything, of Sosa's project can be rescued.

Is knowledge of special value? Even if the argument from the knowledge norm of assertion does not work, there is another argument that Sosa offers at a later stage of the paper (2010b: §V) and that still looks promising. Sosa points out that performances not only have the first order or fundamental aim-to attain result $R$, say-but automatically have the induced aim of bringing about $R$, i.e. of aptly attaining $R$. For belief this means that belief not only has truth as its aim but also knowledge as an induced aim.

At the same time, rational coherence requires agents to prefer satisfaction of their preferences to frustration. As a result, since any agent who endeavours to attain some aim clearly prefers attainment over non-attainment, rational coherence requires an agent who endeavours to attain some aim to prefer success over failure. Since beliefs are performances that aim both at truth (fundamentally) and knowledge (inducedly), rational coherence requires agents to prefer knowledgeattainment of both the fundamental and the induced aim of the performance- to mere true belief - attainment of only one of the performance's aims. The special value of knowledge can thus be preserved. 
From this way of explaining the special value of knowledge, Sosa can also argue for a knowledge norm of belief. Given that beliefs are performances that aim at both truth and knowledge, beliefs that fall short of knowledge fail to attain one of their aims and, as a result, are defective. They fail to satisfy a minimal standard criterion for performance, which, by Sosa's lights, is one kind of performance norm. In this way, knowledge is a norm of belief. Conversely, Sosa can argue from this knowledge norm of belief to the special value of knowledge. Since rational coherence requires agents to prefer success over failure and a defective performance is a kind of failure, rational coherence requires agents to prefer non-defective performances over defective ones. Given that beliefs are performances and that beliefs are defective unless they qualify as knowledge (i.e. the above knowledge norm holds), it follows that rational coherence requires agents to prefer knowledge over belief that falls short of knowledge. While Sosa's argument for the equivalence of the knowledge norm of assertion and the special value of knowledge fails, an argument for the equivalence of the knowledge norm of belief and the special value of knowledge may still be viable for him.

\section{Conclusion}

In conclusion, I have argued that Sosa's arguments for the equivalence thesis and the knowledge norm of assertion both fail. The former rests on a problematic conception of belief (ACB). As opposed to that, the latter fails because, as cases of selfless assertion suggest, sincerity is not a norm and certainly not an epistemic norm of assertion. Even if knowledge is not the norm of assertion and the equivalence thesis does not hold, the ensuing rescue mission turns out to be promising for the thesis that knowledge has special value and even for the thesis that the special value of knowledge is equivalent to the thesis that knowledge is a norm of belief.

Acknowledgments Thanks to Ernest Sosa and an anonymous referee for helpful comments on this paper.

\section{References}

Lackey, J. (2006). Learning from words. Philosophy and Phenomenological Research, 73, 77-101.

Lackey, J. (2007). Norms of assertion. Noûs, 41, 594-626.

Lackey, J. (2008). Learning from words: Testimony as a source of knowledge. Oxford: Oxford University Press.

Sosa, E. (2007). A virtue epistemology. Apt belief and reflective knowledge (Vol. 1). Oxford: Oxford University Press.

Sosa, E. (2010a). How competence matters in epistemology. Philosophical Perspectives, 24, 465-475.

Sosa, E. (2010b). Value matters in epistemology. Journal of Philosophy, 107, 167-190.

Sosa, E. (2011). Knowing full-well. Princeton, NJ: Princeton University Press. 